\title{
SEROPREVALENCE OF HEPATITIS C VIRUS AMONG BLOOD DONORS IN A TERTIARY CARE CENTRE IN KERALA
}

\author{
Lekshmi L. Rajan1, M. S. Suma², Kala V. L3, Harikumar $S^{4}$ \\ ${ }^{1}$ Assistant Professor, Department of Transfusion Medicine and Immunohematology, Government Medical College, Kottayam, Kerala. \\ ${ }^{2}$ Associate Professor, Department of Transfusion Medicine and Immunohematology, Government Medical College, Kottayam, Kerala \\ ${ }^{3}$ Assistant Professor, Department of Transfusion Medicine and Immunohematology, Government Medical College, Kottayam, Kerala. \\ ${ }^{4} D P M, N H M$, Kerala.
}

\section{ABSTRACT}

\section{BACKGROUND}

Transfusion transmitted infections continue to be a threat to safe blood transfusion practices. The problems of window period is an important aspect in the detection of viral infections. Most persons infected with Hepatitis C are asymptomatic without any history of jaundice, but have chronic hepatitis with a few progressing to liver failure. Prevalence study helps to understand the depth of the problem in the community and also emphasises on more widespread use of newer diagnostic procedures to overcome the long window period in screening for Hepatitis $\mathrm{C}$.

\section{MATERIALS AND METHODS}

This is a descriptive study conducted in the tertiary care settings of a Government Medical College in Kerala. Retrospective data pertaining to screening of blood units in the blood bank of the Institution during the study period from 2012 to 2016 were collected from the records and analysed to assess the prevalence of seroreactive Hepatitis C.

\section{RESULTS}

A total of 93,023 blood units were collected during the five-year period, of which 15,382 units were donated in outreach camps. Males were the predominant donors. There were 87,194 male donors during this period, while female donors accounted for 5829 units; $89 \%$ females donated in outreach camps. Most of the donors were in 18 - 40 years' age group; 67 samples were found to be seroreactive to Hepatitis C, of which only 2 were females. The overall prevalence of seroreactive Hepatitis C is $0.072 \%$. Hepatitis C accounts for one-fourth of the total transfusion transmitted infections among blood donors.

\section{CONCLUSION}

Although, overall prevalence of Hepatitis C in this area is low, it is persistent and significant and contributes to a one-fourth of transfusion transmitted infections. Blood component use increases the risk of transmission of infection to multiple recipients. Transfusion of blood and blood components is a potential source of Hepatitis C. Since there are no currently available vaccines against Hepatitis $\mathrm{C}$, transfusion safety is crucial for preventing the transmission of Hepatitis $\mathrm{C}$.

\section{KEYWORDS}

Seroreactivity, Prevalence, Hepatitis C, Blood Donors.

HOW TO CITE THIS ARTICLE: Rajan LL, Suma MS, Kala VL, et al. Seroprevalence of hepatitis C virus among blood donors in a tertiary care centre in Kerala. J. Evolution Med. Dent. Sci. 2017;6(50):3852-3856, DOI: 10.14260/Jemds/2017/832

\section{BACKGROUND \\ Transfusion of blood and blood products can lead to} infectious and non-infectious complications in the recipients. Hepatitis C Virus (HCV) discovered in 1989 belongs to Flaviviridae family. It was previously known as Non A - Non B Hepatitis virus found associated with transfusion transmitted hepatitis. HCV is a lipid-enveloped, single-stranded RNA virus. The majority of HCV infections are asymptomatic. HCV is usually acquired by percutaneous exposure. High risk groups include intravenous drug users, transfusion recipients, transplant recipients, those using immunoglobulins, haemodialysis patients and healthcare workers.

Financial or Other, Competing Interest: None.

Submission 01-06-2017, Peer Review 13-06-2017,

Acceptance 16-06-2017, Published 22-06-2017.

Corresponding Author:

Dr. Lekshmi L. Rajan,

Department of Transfusion

Medicine and Immunohematology,

Government Medical College, Kottayam, Kerala.

E-mail:lekshmraj@gmail.com

DOI: $10.14260 /$ jemds $/ 2017 / 832$
Tattooing, acupuncture, use of unsterile needle for rituals and cultural practices, medical treatment and vaccination may result in transmission of HCV. HCV can be transmitted sexually and vertically from mother to child. Even though sexual and vertical transmission is uncommon, co-infection with HIV may increase transmission by these routes. HCV may also transmit to household contacts through percutaneous exposure. $1,2,3$

Hepatitis C is distributed worldwide. Globally, Hepatitis C virus create a huge burden of disease in the form of chronic progressive liver diseases. Hepatitis $\mathrm{C}$ has become one of the major causes of liver cancer and one of the most common indication for liver transplantation. In 2015, an estimated 71 million people were living with chronic HCV infection according to WHO and only 20 percent of those infected with HCV had been tested to know the status. It is very important to study the prevalence of Hepatitis $C$ in a population. There is a delay between the time an individual is exposed to an infection and the time the donor screening test for the infection becomes positive. Blood donated during this window period could transmit infection. Asymptomatic infection, carrier state, long incubation period and long window period create a real threat to transfusion safety. ${ }^{1}$ 
Blood donors represent a group of healthy people in a community. Prevalence among blood donors reflects the pattern of infection in general population. It is very important to screen all blood prior to transfusion for Hepatitis C. In India, The Drug and Cosmetic Act 1992 mandates the testing of each unit of blood for viral markers of Human Immunodeficiency Virus, Hepatitis B, Malaria and Syphilis. Mandatory testing for HCV antibody in blood donors started in 2001.4

Infectious disease screening of donors is accomplished by questioning of potential donors, exclusion of individuals with an increased risk of infection and testing of donor blood.

\section{MATERIALS AND METHODS}

The study was conducted in a tertiary care centre in Kerala, which is also a Government Medical College in Kerala. The study is a descriptive study based on retrospective collection of data from available records. The data was collected from the blood donor records and registers pertaining to the 5year period from 2012 to 2016 . All blood units collected in blood banks are tested mandatory for five diseases. Consent for testing was obtained from each donor prior to blood donation. Healthy blood donors were selected by a thorough screening process, which included a detailed history taking and physical examination. Donor screening process for infectious diseases involved a combination of donor education and self-deferral, donor questioning and testing. The donor serum samples were analysed to detect anti-HCV antibodies by third generation ELISA test. All the samples that were found positive by ELISA on initial testing were repeated in duplicate with the same samples. Samples that were found reactive on repeat testing were considered as positive and included in the study. Any equivocal or indeterminate samples were also discarded considering the safety of blood transfusion, but not included in the study. Seroreactivity to Hepatitis $\mathrm{C}$ virus is recorded in the respective screening register. Blood bank conducted outreach camps to promote voluntary blood donations. Outreach camps were conducted mainly in colleges, schools, offices, blood collection bus and other institutions. All the donor units collected during the study period in the blood bank as well as outreach camps were included in the study leading to a sample size of 93,023. Descriptive analysis was done on collected data. Estimation of total prevalence during the period was done along with the annual prevalence from the collected data to find out trends. The proportion of positive cases among male and female donors was estimated and Chi square test for proportions was done to find out any significant difference between them. The proportion of positive cases among total donors was also estimated for each year and a Chi-square test for proportions was done to find out any significant change in annual prevalence over the 5-year study period.

\section{RESULTS}

All the donor units collected during the study period from January 2012 to December 2016 by the blood bank were included in the study. The data was collected from the blood donor records and registers pertaining to the 5-year period from 2012 to 2016. A total of 93,023 blood units was collected during the study period. Blood was collected from donors who visited the blood bank and also from donors in outreach camps conducted in colleges and other institutions. All the donations were voluntary in nature. Descriptive analysis was done on collected data. Out of 93,023 donors, 87,194 (93.74\%) were males and 5829 (6.26\%) were females. The distribution of donors according to their sex and place of donation is given in Table No. 1 and 2 .

\begin{tabular}{|c|c|c|c|}
\hline Year of Study & Male & Female & Total \\
\hline 2012 & 16595 & 565 & 17160 \\
\hline 2013 & 15342 & 1023 & 16365 \\
\hline 2014 & 16207 & 1656 & 17863 \\
\hline 2015 & 18415 & 1644 & 20059 \\
\hline 2016 & 20635 & 941 & 21576 \\
\hline Total & $\begin{array}{c}\mathbf{8 7 1 9 4} \\
(\mathbf{9 3 . 7 4 \% )}\end{array}$ & $\begin{array}{c}\mathbf{5 8 2 9} \\
\mathbf{( 6 . 2 6 \% )}\end{array}$ & $\mathbf{9 3 0 2 3}$ \\
\hline \multicolumn{4}{|c|}{ Table No. 1. Distribution of Donors according to Sex } \\
\hline
\end{tabular}

\begin{tabular}{|c|c|c|c|c|c|c|c|}
\hline $\begin{array}{c}\text { Year } \\
\text { of } \\
\text { Study }\end{array}$ & \multicolumn{3}{|c|}{$\begin{array}{c}\text { Blood Collected } \\
\text { in Blood Bank }\end{array}$} & \multicolumn{3}{c|}{$\begin{array}{c}\text { Blood Collected in } \\
\text { Outreach Camps }\end{array}$} & $\begin{array}{c}\text { Total } \\
\text { (A+B) }\end{array}$ \\
\hline & Male & Female & $\begin{array}{c}\text { Total } \\
\text { (A) }\end{array}$ & Male & Female & $\begin{array}{c}\text { Total } \\
\text { (B) }\end{array}$ & \\
\hline 2012 & 15409 & 110 & 15519 & 1186 & 455 & 1641 & 17160 \\
\hline 2013 & 13392 & 72 & 13464 & 1950 & 951 & 2901 & 16365 \\
\hline 2014 & 13807 & 71 & 13878 & 2400 & 1585 & 3985 & 17863 \\
\hline 2015 & 16015 & 145 & 16160 & 2400 & 1499 & 3899 & 20059 \\
\hline 2016 & 18387 & 233 & 18620 & 2248 & 708 & 2956 & 21576 \\
\hline Total & $\mathbf{7 7 0 1 0}$ & $\mathbf{6 3 1}$ & $\begin{array}{c}\mathbf{7 7 6 4 1} \\
\text { (83.46\%) }\end{array}$ & 10184 & $\mathbf{5 1 9 8}$ & $\begin{array}{c}\mathbf{1 5 3 8 2} \\
\text { (16.54\%) }\end{array}$ & $\mathbf{9 3 0 2 3}$ \\
\hline Table No. 2. Distribution of Donors according to Place of \\
Donation
\end{tabular}

Of the total 93,023 units, blood collected from donors who donated in blood bank is $77,641(83.46 \%)$ and outreach camps is $15,382(16.54 \%)$.

The total number of male donors during this period was 87,194 ; of the male donors $88 \%(77,010)$ donated blood in blood banks, while out of 5829 females 5198 (89\%) donated blood in outreach camps especially in colleges. Female donors were more in outreach camps. Total number of donors are also increasing every year showing more and more motivated young people are donating and also the increased demand for blood and blood products.

Females accounted for 5198 (33.8\%) blood donations in outreach camps and only $631(0.81 \%)$ blood donations in the blood bank. Thus, conducting more outreach camps promote female donations. 95\% donors belonged to the age group 18 40 years.

The donor screening process involved a combination of donor education and self-deferral, donor questioning and testing. All samples were tested mandatory for five Transfusion Transmitted Infections (TTI), namely HIV antibody detection test, HBsAg antigen detection test and HCV antibody detection test, Malarial antigen detection test and Syphilitic antibody detection test. Screening tests used for Hepatitis C antibody detection was third generation ELISA kit. Repeatedly reactive samples are considered positive and included in the study. Any equivocal or indeterminate samples were also discarded considering the safety of blood transfusion, but not included in the study.

Out of 93,023 donor samples tested in five-year study period, 268 samples were found positive to Transfusion 
Transmitted Infections (TTI); $0.29 \%$ is the prevalence of transfusion transmitted infections among blood donors during the study period.

In the total of 268 donor samples which were found reactive to these transfusion transmitted infections, of which 67 (25\%) were due to Hepatitis C. Hepatitis C accounted for one-fourth of the total transfusion transmitted infections. This showed the magnitude of Hepatitis C among the transfusion transmitted infections (Table No. 3).

\begin{tabular}{|c|c|c|}
\hline $\begin{array}{c}\text { Year of } \\
\text { Study }\end{array}$ & $\begin{array}{c}\text { No. of TTI } \\
\text { Reactive Donors }\end{array}$ & $\begin{array}{c}\text { No. of Anti-HCV } \\
\text { Reactive Donors }\end{array}$ \\
\hline 2012 & 41 & $2(4.88 \%)$ \\
\hline 2013 & 32 & $2(6.25 \%)$ \\
\hline 2014 & 79 & $27(34.17 \%)$ \\
\hline 2015 & 52 & $15(28.84 \%)$ \\
\hline 2016 & 64 & $21(32.81 \%)$ \\
\hline Total & $\mathbf{2 6 8}$ & $\mathbf{6 7}(\mathbf{2 5 \% )}$ \\
\hline \multicolumn{2}{|c|}{ Table No. 3. Proportion of HCV Seroreactivity } \\
among all Seroreactive Samples
\end{tabular}

Transfusion transmitted infections were found more during the year 2014. A total of 79 cases. HCV seropositivity was also high during the year of 2014. Hepatitis C accounted for $34.17 \%$ of total TTI during the year 2014 .

Hepatitis C seroreactivity among total donors is calculated to study the prevalence; 67 samples were found reactive to Hepatitis $\mathrm{C}$ antibody testing in the five-year period.

67 samples out of 93,023 donors showed positive reaction to Hepatitis $\mathrm{C}$, thus giving an overall prevalence of $0.072 \%$ during the study period. The prevalence is $0.0746 \%$ among male donors and $0.0343 \%$ among female donors. There is no significant difference in the prevalence of Hepatitis $\mathrm{C}$ between male and female donors during the study period (Table No. 4).

\begin{tabular}{|c|c|c|c|}
\hline & Male Donors & Female Donors & Total \\
\hline Sero-Positive & 65 & 2 & 67 \\
\hline Sero-Negative & 87129 & 5827 & 92956 \\
\hline Total & 87194 & 5829 & 93023 \\
\hline
\end{tabular}

Table No. 4. Comparison of Sero-Positivity among Male and Female Donors ( $P$ value $>0.05$ )

During the study period, peak prevalence is observed during $2014(0.1511 \%)$. A slight decrease in prevalence is obtained in $2015(0.0747 \%)$. Again, a rise in prevalence is obtained in 2016 (0.0933\%). Seroprevalence of Hepatitis C is too low in 2012 and 2013. Hence, we can see an increase in seroprevalence of Hepatitis $\mathrm{C}$ during the study period. There is a persistent trend and there is significant change in the yearly prevalence of Hepatitis C during the study period, ( $\mathrm{p}$ value $<0.001$ ).

The year-wise estimation of prevalence rates are given in Table 5 and Figure 1. It is clearly evident in the Figure that seroprevalence of Hepatitis C is increasing among blood donors and is persisting also.

\begin{tabular}{|c|c|c|c|}
\hline Year & $\begin{array}{c}\text { Total } \\
\text { Number of } \\
\text { Units Collected }\end{array}$ & $\begin{array}{c}\text { Number of } \\
\text { Samples } \\
\text { Seroreactive } \\
\text { to HCV }\end{array}$ & Prevalence \\
\hline 2012 & 17160 & 2 & $0.0116 \%$ \\
\hline 2013 & 16365 & 2 & $0.0122 \%$ \\
\hline 2014 & 17863 & 27 & $0.1511 \%$ \\
\hline 2015 & 20059 & 15 & $0.0747 \%$ \\
\hline 2016 & 21576 & 21 & $0.0933 \%$ \\
\hline Total & $\mathbf{9 3 , 0 2 3}$ & $\mathbf{6 7}$ & $\mathbf{0 . 0 7 2 0 \%}$ \\
\hline Table No. 5. Yearly Estimate of Hepatitis C Prevalence (P \\
value < 0.001) \\
\hline \multicolumn{4}{|r|}{}
\end{tabular}

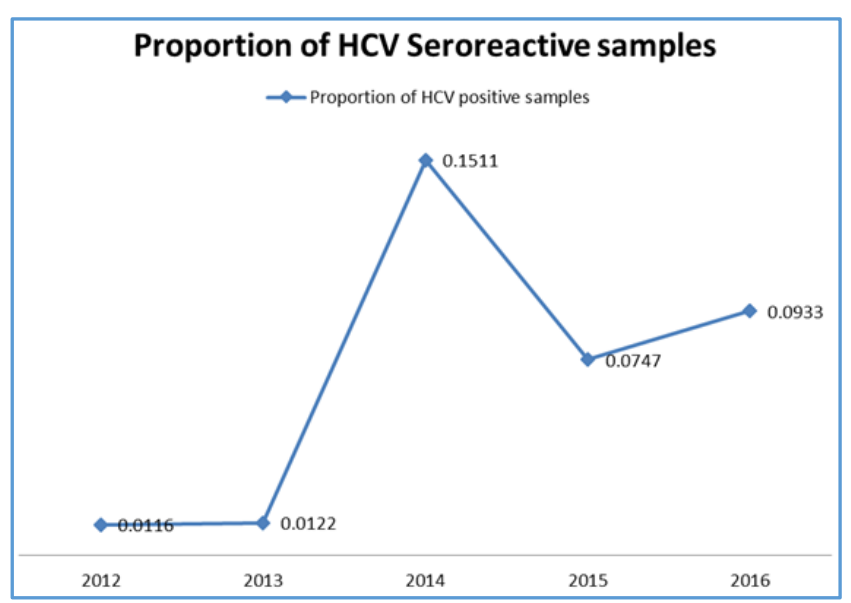

Figure 1. Yearly Trend of Hepatitis C Prevalence

\section{DISCUSSION}

Transfusion of blood and blood products are increasing nowadays leading to the possibility of increased transfusion transmitted infections. Modern transfusion therapy guidelines also advocate component therapy. Thus, infectious agents in one donor may spread to multiple recipients. The problem of window period varies from few days to months depending on the infections and also the tests employed for detection. ELISA method for detection of antigen and antibodies are used widely throughout the country. Nucleic acid amplification tests ensure early detection of virus particles, but are used only in selected centres. Transfusion transmitted infections like HIV/AIDS are showing a decreasing trend nowadays, but the problem of Hepatitis $\mathrm{C}$ is increasing.

According to WHO, the most affected regions are WHO Eastern Mediterranean and European Regions with the prevalence of $2.3 \%$ and $1.5 \%$, respectively. Prevalence of HCV infection in other WHO regions varies from $0.5 \%$ to $1.0 \%$. Depending on the country, Hepatitis $\mathrm{C}$ virus infection can be concentrated in certain populations (for example, among people who inject drugs) and/or in general population. There are multiple strains (or genotypes) of the HCV virus and their distribution varies by region. ${ }^{1}$

HCV has become one of the major causes of liver cancer and one of the most common indication for liver transplantation. There is a high rate of chronicity of about 15 - 85\% following HCV infection. Most patients have asymptomatic infection with no history of jaundice, but have chronic hepatitis with some developing cirrhosis and few progressing to liver failure. Despite a low-to-moderate 
prevalence of $\mathrm{HCV}$, India accounts for a significant share of global HCV infections due to large population.1,2,3

Studies from various part of the country showed a rise in prevalence of Hepatitis C. Long latent period for detection by screening tests is an issue that puts transfusion recipients under threat of acquiring Hepatitis $\mathrm{C}$.

Various studies have been conducted to estimate the prevalence of Hepatitis C. The prevalence rate of anti-HCV seroreactivity was reported to be 1.44 in a study conducted from 1994 to 1999 in Trivandrum, Kerala. ${ }^{5}$ In a 10-year study conducted among blood donors in North India, Makroo et al found $0.39 \%$ donors reactive to HCV antibody detection tests. Seroprevalence of anti-HCV among males is $0.38 \%$ and that of females is $0.36 \% .^{6}$ No significant change in trend in the seroprevalence of anti-HCV antibodies was obtained in a 10year period. The reactivity was maximum in $18-30$ age group and decreases with age. A slight increase in the prevalence of HCV was noted by Makroo et al in a later study. ${ }^{7}$ The study found out that the risk of transfusion transmitted infections are decreasing with respect to HIV, Hepatitis B and Syphilis, but Hepatitis C is increasing. ${ }^{7}$

Prevalence of HCV among hospital-based population was alarmingly high at $7.7 \%$ in a study conducted in Andhra Pradesh, even though the study showed a decreasing trend in transfusion transmitted infections. ${ }^{8}$ A study conducted in Ludhiana showed a prevalence rate of $1.5 \%$, which is similar to many studies conducted in India and other countries like Spain and Japan. ${ }^{9}$

In a study conducted in Vietnam, the prevalence of antiHCV was $0.17 \% .{ }^{10}$ This study reported a high prevalence of Hepatitis $C$ in rural population. The study emphasises the need for Nucleic acid testing instead of ELISA for screening blood prior to transfusion. A study conducted on sickle cell patients in Uganda found HCV prevalence to be high among those receiving blood transfusion. ${ }^{11}$ Blood transfusion is considered as a major contributing factor for transmission of Hepatitis C. This study concluded by saying that blood components prior to transfusion must be screened for Hepatitis $\mathrm{C}$ and transfusion dependent patients must also be screened for Hepatitis C.

Another study from Chandigarh showed HCV prevalence of $0.8 \%, 12$ while a study from Bangladesh showed $0.17 \%$ seroreactivity among blood donors. ${ }^{13}$ Anti-HCV positivity showed wide range of fluctuation from $0.86 \%-2.03 \%$ in a study reported from Punjab. ${ }^{14}$

A seroprevalence of $0.08 \%$ was found in a study conducted in central Kerala among 1200 blood donors, which is similar to the present study. ${ }^{15}$ The seroprevalence of Hepatitis C among donors was conducted in many centres and findings were similar to present study. ${ }^{16,17,18}$ The seroprevalence of Hepatitis $\mathrm{C}$ among donor population in India is $1.8 \%-2.5 \%$, and the community seroprevalence has been reported to be $0.87 \% .{ }^{19}$ In another Kerala-based study by Sandesh et al the prevalence of Hepatitis C is $0.33 \%$ among voluntary blood donors, $0.12 \%$ in job seekers in Middle East Asia and $0.24 \%$ in normal population. IV drug abusers have also been found to have a high prevalence of anti-HCV antibodies. ${ }^{20}$

\begin{tabular}{|c|c|}
\hline South Kerala $^{5}$ & $1.44 \%$ \\
\hline Central Kerala $^{15}$ & $0.08 \%$ \\
\hline North Kerala $^{20}$ & $0.33 \%$ \\
\hline
\end{tabular}

\begin{tabular}{l|l} 
Present Study & $0.072 \%$
\end{tabular}

\section{Table No. 6. Comparison with Other Studies from Kerala}

The prevalence of Hepatitis C is low in present study when compared to other similar studies. Refer Table No. 6 . The donors were selected by trained medical staff after a careful history taking and physical examination. Counselling prior to donation, self-deferral by donors, exclusion of donors with high-risk behaviour and setting up a long deferral period for those with history of jaundice and history of contact with jaundiced patients reduced the seroprevalence.

Many seropositive donors did not give a history of hepatitis in the past on retrospective enquiry. Some remembered history of hepatitis in close friends, in hostel and at home. Few gave history of hospitalisation and injectable drugs usage during their stay in other parts of India. All these suggest asymptomatic infection with Hepatitis C. Even though it is very essential to screen all transfusion recipients for Hepatitis C, only a minority is exposed to transfusion. Common modes of spread of infection in community is unsafe injections, dental procedures, sharing of needles in intravenous drug abuse, unsterile medical procedures, tattooing, skin piercing, etc. Infection is seen more in those with high-risk behaviour. Co-infection with HIV and other hepatitis may lead to chronic carrier state.

Like other studies, males were the predominant donors in blood banks. Female donors were donating in outreach camps. Conducting more outreach camps promote voluntary blood donation and female participation. Voluntary blood donation ensures safe blood to an extent.

Need for blood and blood products are increasing. Blood collection was increasing yearly during the study period. Transfusion transmitted infections were also showing a rising trend with peak number obtained in 2014. ELISA is a highly sensitive test and difference in the sensitivity of ELISA kits used alters seroreactivity. All seropositive cases have to be confirmed by repeating antibody screening after an interval of three months and other nucleic acid tests.

In the present study, Hepatitis C prevalence is estimated over a five-year period with a peak value obtained in 2014 and coming down in 2015 and 2016. Male donors started ear piercing and tattooing during this period. It is essential to screen for Hepatitis C in those who had done skin piercing and tattooing. Even though the prevalence in the present study is low, it accounts for $25 \%$ of the total transfusion transmitted infections among blood donors during the study period.

Effective screening tests are required to prevent transmission of Hepatitis $\mathrm{C}$ to transfusion recipients. Newer techniques such as Nucleic acid amplification test for Hepatitis C RNA should be employed for screening blood samples prior to transfusion and can increase transfusion safety. It is also an ethical imperative to provide more widespread availability of such tests, so that only safe blood components are transfused.

\section{Limitations of the Study}

The study is a record-based data collection. Different kits were used for testing anti-HCV antibodies at different point of time. Third generation ELISA kits were used. Sensitivity and specificity might vary with manufacturers. 


\section{CONCLUSION}

Hepatitis is emerging as an important infectious disease worldwide. Transfusion transmitted Hepatitis, especially Hepatitis C is an important public health problem as it is asymptomatic with a long incubation period and chronicity. The demand on blood products are increasing daily. Component therapy increases the risk of transferring infections to multiple recipients. In spite of the low prevalence, the infection shows a rising trend in the number of seroreactive cases in recent years. There is presently no vaccine available for preventing Hepatitis $\mathrm{C}$ and the only recourse is to raise transfusion safety. Strict donor recruitment process, proper history taking, predonation counselling, promoting voluntary blood donation, testing for anti-HCV antibodies all reduce the chance of transfusiontransmitted hepatitis. Nucleic acid detection tests surely reduce the window period and aids in effective screening for Hepatitis C. The present study emphasises the need of newer diagnostic aids in the detection of Hepatitis C.

\section{REFERENCES}

[1] WHO fact sheet on Hepatitis C. http://www.who.int/mediacentre/factsheets/fs164/e n/ 2017.

[2] CDC Hepatitis C https://wwwnc.cdc.gov/travel/yellowbook/2016/inf ectious-diseases-related-to-travel/hepatitis-c 2017.

[3] WHO guidelines for donor selection. http://www.who.int/bloodsafety/publications/bts guideline donor suitability/en/ 2017.

[4] DGHS guidelines by CDSCO (Central Drug Standard Control Organisation) http://cdsco.nic.in/forms/list. 2017.

[5] Mathai J, Sulochana PV, Satyabhama S, et al. Profile of transfusion transmissible infections and associated risk factors among blood donors of Kerala. Indian Journal of Patho Micro 2002;45(3):319-22.

[6] Makroo RN, Walia RS, Chowdhry $M$, et al. Seroprevalence of anti-HCV antibodies among blood donors of north India. Indian $J$ Med Res 2013;138(1):125-8.

[7] Makroo RN, Hedge V, Chowdery $M$, et al. Seroprevalence of infectious markers and their trends in blood donors in a hospital based blood bank in north India. IJMR 2015;142(3):317-22.

[8] Bhawani Y. Seroprevalence of transfusion transmissible infections among blood donors in a tertiary care hospital in Andra Pradesh. Biology and Medicine 2008;2(4).
[9] Gupta N, Kaur A. Prevalence of Hepatitis C antibodies in healthy blood donors. Indian Journal of Community Medicine 2002;27(1):39-41.

[10] Le Viet, Lan NTN, Ty Xuan P, et al. Prevalence of hepatitis $B$ and Hepatitis $C$ virus infections in potential blood donors in rural Vietnam. Indian Jour of Med Res 2012;136(1):74-81.

[11] Namasopo SO, Ndugwa C, Tumwine JK. Hepatitis C and blood transfusion among children attending the Sickle cell clinic at Mulago Hospital, Ugand. African Health Sciences 2013;13(2):255-60.

[12] Kaur G, Basu S, Kaur R, et al. Patterns of infections among blood donors in a tertiary care centre: a retrospective study. The National Medical Journal of India 2010;23(3):147-9.

[13] Uddin MPK, Morshed AMA. Predominance of HBsAg (+ve) and Anti-HCV positivity among blood donors: experience in a private hospital of Dhaka, Bangladesh. J Blood Disorders Transf 2013;4:154.

[14] Kaur H, Mannan R, Manjari M. Seroprevalence of the blood borne infection in blood donors: our 11 year (2001 -2011) experience in a tertiary care teaching hospital at Amritsar (Punjab). International Journal of Advanced Research 2014;2(6):967-71.

[15] Shailaja TS, MohanKumar A, Sankari D, et al. Seroprevalence of Hepatitis B and Hepatitis C viral infections in Central Kerala. Indian Journal of Applied Research 2016;6(5):39-41.

[16] Shah N, Shah JM, Jhaveri P, et al. Seroprevalence of HBV, HCV HIV and syphilis among blood donors at a tertiary care teaching hospital in Western India. Gujarat Medical Journal 2013;68(2):35-9.

[17] Kumar A, Sharma S, Ingole N, et al. Rising trends of HCV infection over a period of 4 years among blood donors in central India: a retrospective study. International Journal of Medicine and Public Health 2013;3(4):240-3.

[18] Shemin R, Geethangali G. Seroprevalence of Hepatitis $\mathrm{B}$ and Hepatitis $\mathrm{C}$ virus infection among healthy blood donors in a tertiary care hospital: a retrospective study. Global Journal for Research Analysis 2016;5(3): 326-8.

[19] Kumar SP, Choudhuri G. Hepatitis C: the Indian scenario. Physician's Digest 2005.

[20] Sandesh K, Varghese T, Harikumar R, et al. Prevalence of Hepatitis B and C in the normal population and high risk groups in north Kerala. Trop Gastroenterol 2006;27(2):80-3. 